\title{
Is an Appropriate Revascularization Selected for Unprotected Left Main Coronary Artery Disease?
}

\author{
Ryo Naito, MD; Katsumi Miyauchi, MD
}

I mproved devices related to percutaneous coronary intervention (PCI) and increased operator skill have expanded the indications for PCI to a wide range of coronary artery disease (CAD), such as multivessel CAD or unprotected left main CAD (ULMCAD). Specifically, ULMCAD was previously a contraindication for PCI. Several recent clinical trials demonstrated favorable results following PCI for the treatment of ULMCAD compared with coronary artery bypass grafting (CABG). ${ }^{1-3}$ This evidence prompted updating of the guidelines for the treatment of ULMCAD. However, the number of patients in those trials was not sufficient and, furthermore, most of the trials were conducted in Western countries. Therefore, it is of great interest to examine the clinical outcomes of patients with ULMCAD treated with PCI or CABG in a Japanese population, which differs from populations in Western countries regarding dietary habits, various comorbid diseases, and the incidence of CAD. ${ }^{4}$

\section{Article p 1282}

Previously, Shiomi and colleagues reported the 3-year follow-up data from a large-scale Japanese database, the CREDO-Kyoto PCI/CABG Registry. ${ }^{5}$ The authors reported that the 3-year composite endpoint of all-cause death, myocardial infarction (MI) and stroke was comparable between PCI with drug-eluting stent (DES) and CABG (off-pump CABG;
$65 \%$ ). In patients with low or intermediate SYNTAX scores, the rate of serious cardiovascular events was not different between PCI and CABG. However, the risk of events was markedly higher in the PCI group with high SYNTAX scores compared with the CABG group.

In this issue of the Journal, Shiomi et $\mathrm{al}^{6}$ report the 5-year extended follow-up data. The cumulative 5-year incidence of the primary endpoints (death, MI and stroke) was significantly higher in the PCI group than in the CABG group (34.5 vs. $24.1 \%, \mathrm{P}<0.001)$. The adjusted hazard ratio (HR) for the primary endpoint in the PCI group was 1.48 (95\% confidence interval (CI) $1.07-1.93, \mathrm{P}=0.02)$. No difference was observed in the adjusted HR for all-cause mortality between the groups (adjusted HR 1.32, 95\% CI 0.90-1.93, P=0.16), whereas the adjusted HR for the following outcomes were significantly higher in the PCI group (cardiac death: adjusted HR 2.00, 95\% CI 1.10-3.63, P=0.02; MI: adjusted HR 2.25, 95\% CI 1.044.88, $\mathrm{P}=0.04$; revascularization: adjusted $\mathrm{HR} 4.31,95 \% \mathrm{CI}$ 2.97-6.26, $\mathrm{P}<0.001)$. Subgroup analyses stratified by SYNTAX score (low: $<23$, intermediate: $23-32$, high: $>32$ ) were performed for $92.7 \%$ of the whole study population. The adjusted HR for the primary endpoint was not different in patients with a low or intermediate SYNTAX score. The event rate in patients with a high SYNTAX score was significantly higher in the PCI group (adjusted HR 2.09, 95\% CI 1.26-3.46, $\mathrm{P}=0.004)$. The results from this relatively large-scale, prospec-

\begin{tabular}{|c|c|c|}
\hline \multirow[t]{2}{*}{ Anatomic setting } & \multicolumn{2}{|c|}{$\begin{array}{c}\text { Class of recommendation } \\
\text { level of evidence }\end{array}$} \\
\hline & $\mathbf{P C l}$ & CABG \\
\hline \multicolumn{3}{|l|}{ JCS $^{*}$} \\
\hline Ostial or trunk with or without 1-vessel disease & $\mathrm{Ilb} / \mathrm{C}$ & $\mathrm{I} / \mathrm{A}$ \\
\hline Bifurcation with or without 1 -vessel disease & $\mathrm{III} / \mathrm{C}$ & I/A \\
\hline Multivessel disease & $\mathrm{III} / \mathrm{C}$ & I/A \\
\hline \multicolumn{3}{|l|}{ ACCF/AHA** } \\
\hline SYNTAX $<23$, ostial or trunk with significantly increased surgical risk & $\mathrm{Ila} / \mathrm{B}$ & I/B \\
\hline SYNTAX $<33$ or bifurcation with increased surgical risk & $\mathrm{Ilb} / \mathrm{B}$ & I/B \\
\hline Unfavorable anatomy for $\mathrm{PCl}$ & III/B & I/B \\
\hline
\end{tabular}

*Adopted with permission from JCS Joint Working Group. ${ }^{* \star}$ Adopted with permission from Finn SD, et al. ${ }^{8}$ CABG, coronary artery bypass grafting; $\mathrm{PCl}$, percutaneous coronary intervention; ULMCAD, unprotected left main coronary artery disease.

The opinions expressed in this article are not necessarily those of the editors or of the Japanese Circulation Society.

Received April 20, 2015; accepted April 21, 2015; released online May 9, 2015

Department of Cardiology, Juntendo University School of Medicine, Tokyo, Japan

Mailing address: Katsumi Miyauchi, MD, Department of Cardiology, Juntendo University Graduate School of Medicine, 2-1-1 Hongo,

Bunkyo-ku, Tokyo 113-8421, Japan. E-mail: ktmmy@med.juntendo.ac.jp

ISSN-1346-9843 doi:10.1253/circj.CJ-15-0439

All rights are reserved to the Japanese Circulation Society. For permissions, please e-mail: cj@j-circ.or.jp 


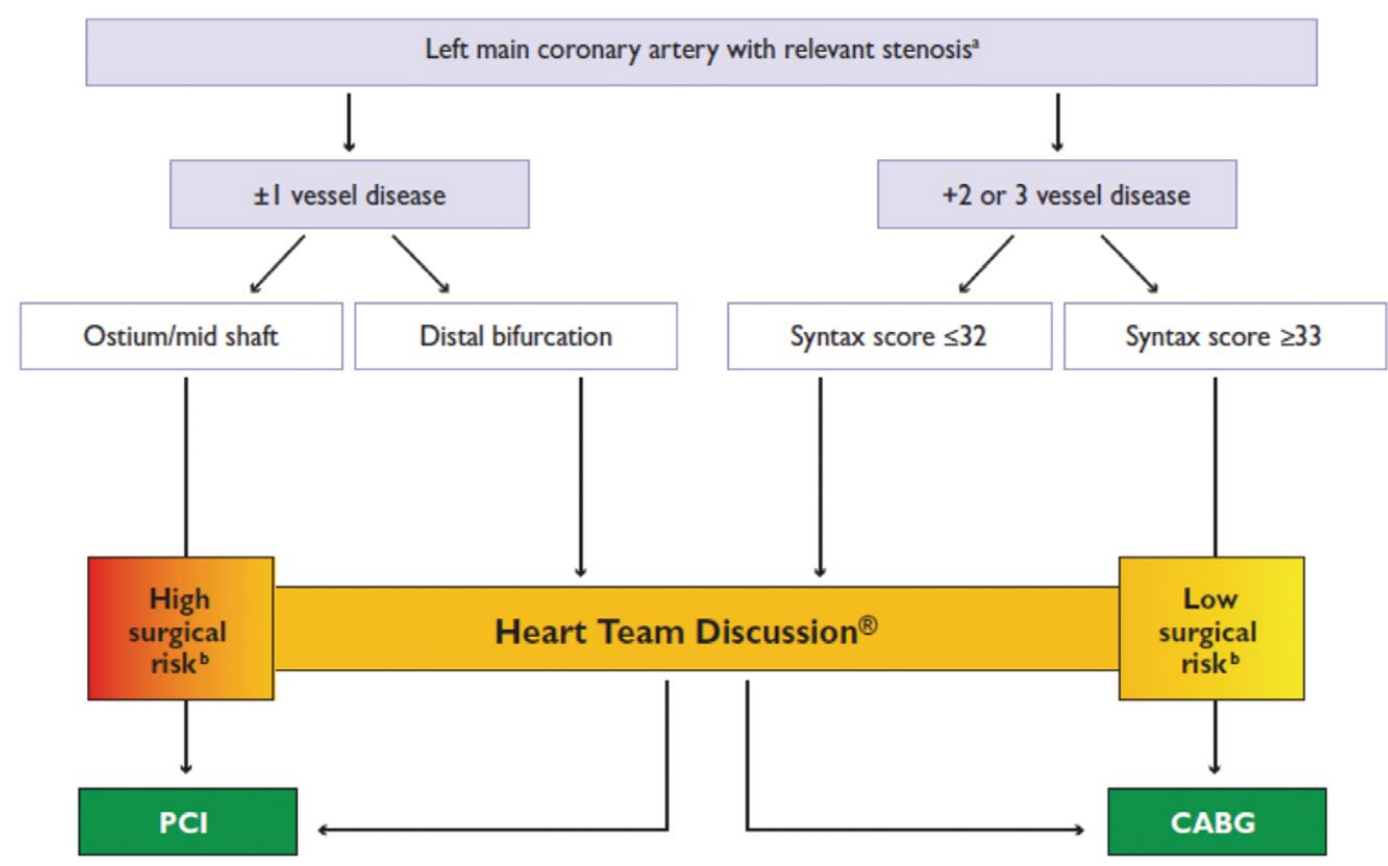

Figure. Heart team discussion considering anatomical complexity and surgical risk is essential when selecting the revascularization strategy in patients with left main coronary artery disease. Percutaneous coronary intervention (PCI) or coronary artery bypass grafting (CABG) for stable coronary artery disease with left main coronary artery involvement. (Adopted with permission from Task Force Members, Montalescot G, et al. ${ }^{9}$ )

tive cohort study were consistent with both the 3-year followup data of the identical cohort and the 5-year results from the SYNTAX trial.

In the current guidelines for ULMCAD treatment from the Japanese Circulation Society, CABG is indicated as Class I, level of evidence (LOE) A. PCI is Class II b, LOE C to ostial or trunk LM lesions with or without 1 -vessel disease (Table). ${ }^{7}$ ULMCAD with a bifurcation lesion or multivessel disease is a contraindication for PCI. The 2012 American College of Cardiology Foundation/American Heart Association (ACCF/ AHA) Task Force guideline states that $\mathrm{CABG}$ is considered to be Class I, LOE B, and PCI is Class IIa, LOE B in patients with a low SYNTAX score and a significantly high surgical risk, and Class IIb, LOE B in patients with a low to intermediate SYNTAX score and a high surgical risk (Table). ${ }^{8}$ Recently, the Heart Team has gained recognition for their value in reaching a consensus regarding revascularization therapy selection. A guideline of the European Society of Cardiology (ESC) suggests an algorithm (Figure) that considers both the SYNTAX score and surgical risk when deciding on a specific revascularization therapy. ${ }^{9}$ The guideline clearly states the importance of the Heart Team discussion.

Because this study was from a large-scale Japanese registry and the long-term clinical outcomes were evaluated, these results could be applied to Japanese clinical practice. Furthermore, the results would update the clinical guidelines for ULMCAD treatment. Meanwhile, we should not overlook that the data regarding surgical risk, such as the European system for cardiac operative risk evaluation score (EuroSCORE) and the Society of Thoracic Surgeons (STS) score, which are important when deciding on a revascularization strategy, were not provided in this study. In addition, selection bias might have affected the results, although the study design was observational and the selection of revascularization therapy was decided at each institution. Because the data were registrybased, unmeasured factors, such as the features of individual institutions, intention of referring physicians, notion of the patients or their families, and comorbid conditions of the patients, affected the selection of revascularization treatment. When selecting a revascularization therapy in clinical practice, not only the anatomical complexity but also the patient's background, such as age, comorbid diseases and frailty, should be considered. Furthermore, we should recognize that there is still a subset of patients who are beyond the current evidencebased clinical practice and will not be correctly discriminated by scoring systems alone. In those patients, the necessity of the Heart Team approach, such as thorough discussion among cardiologists, cardiovascular surgeons and other medical staff and a detailed explanation to the patient and the family, should be more emphasized.

Finally, accompanying the evolution of PCI represented by newer DES that are superior to the first-generation DES, complete revascularization with new devices may bridge the gap in the clinical endpoints between PCI and CABG, even in patients with a high SYNTAX score.

\section{Disclosures}

K.M. has received speakers' Bureau/Honoraria from MSD K.K., DaiichiSankyo Company, Limited, Bayer Yakuhin, Ltd, AstraZeneca K.K., Mochida Pharmaceutical Co, Ltd, Takeda Pharmaceutical Co, Ltd, and Astellas Pharma Inc. 


\section{References}

1. Chieffo A, Magni V, Latib A, Maisano F, Ielasi A, Montorfano M, et al. 5-year outcomes following percutaneous coronary intervention with drug-eluting stent implantation versus coronary artery bypass graft for unprotected left main coronary artery lesions the Milan experience. JACC Cardiovasc Interv 2010; 3: 595-601.

2. Park DW, Seung KB, Kim YH, Lee JY, Kim WJ, Kang SJ, et al. Long-term safety and efficacy of stenting versus coronary artery bypass grafting for unprotected left main coronary artery disease: 5-year results from the MAIN-COMPARE (Revascularization for Unprotected Left Main Coronary Artery Stenosis: Comparison of Percutaneous Coronary Angioplasty Versus Surgical Revascularization) registry. J Am Coll Cardiol 2010; 56: 117-124.

3. Morice MC, Serruys PW, Kappetein AP, Feldman TE, Ståhle E, Colombo A, et al. Five-year outcomes in patients with left main disease treated with either percutaneous coronary intervention or coronary artery bypass grafting in the synergy between percutaneous coronary intervention with taxus and cardiac surgery trial. Circulation 2014; 129: 2388-2394.

4. JCS Joint Working Group. Guidelines for the primary prevention of ischemic heart disease revised version (JCS 2012). http://www.j-circ. or.jp/guideline/pdf/JCS2012_shimamoto_h.pdf (in Japanese).

5. Shiomi H, Morimoto T, Hayano M, Furukawa Y, Nakagawa Y, Tazaki J, et al. Comparison of long-term outcome after percutaneous coronary intervention versus coronary artery bypass grafting in patients with unprotected left main coronary artery disease (from the
CREDO-Kyoto PCI/CABG Registry Cohort-2). Am J Cardiol 2012; 110: $924-932$.

6. Shiomi H, Morimoto T, Furukawa Y, Nakagawa Y, Sakata R, Okabayashi $\mathrm{H}$, et al; on behalf of the CREDO-Kyoto PCI/CABG registry cohort-2 investigators. Comparison of percutaneous coronary intervention with coronary artery bypass grafting in unprotected left main coronary artery disease: 5-year outcome from CREDOKyoto PCI/CABG Registry Cohort-2. Circ J 2015; 79: 1282-1289.

7. JCS Joint Working Group. Guidelines for elective percutaneous coronary intervention in patients with stable coronary artery disease (JCS 2011): Digest version. Circ J 2013; 77: 1590-1607.

8. Fihn SD, Gardin JM, Abrams J, Berra K, Blankenship JC, Dallas AP, et al. $2012 \mathrm{ACCF} / \mathrm{AHA} / \mathrm{ACP} / \mathrm{AATS} / \mathrm{PCNA} / \mathrm{SCAI} / \mathrm{STS}$ guideline for the diagnosis and management of patients with stable ischemic heart disease: A report of the American College of Cardiology Foundation/American Heart Association task force on practice guidelines, and the American College of Physicians, American Association for Thoracic Surgery, Preventive Cardiovascular Nurses Association, Society for Cardiovascular Angiography and Interventions, and Society of Thoracic Surgeons. Circulation 2012; 126: e354-e471, doi:10.1161/CIR.0b013e318277d6a0.

9. Task Force Members, Montalescot G, Sechtem U, Achenbach S, Andreotti F, Arden C, Budaj A, et al. 2013 ESC guidelines on the management of stable coronary artery disease: The Task Force on the management of stable coronary artery disease of the European Society of Cardiology. Eur Heart J 2013; 34: 2949-3003. 